\title{
SOLUSI DARI PERSAMAAN CAUCHY-EULER NONHOMOGEN KASUS LOGARITMIK
}

\author{
I Gede Putu Miki Sukadana ${ }^{1 \S}$, I Nyoman Widana ${ }^{2}$, Ketut Jayanegara ${ }^{3}$ \\ ${ }^{1}$ Program Studi Matematika, Fakultas MIPA-Universitas Udayana [Email: miki_putu@yahoo.co.id] \\ ${ }^{2}$ Program Studi Matematika, Fakultas MIPA-Universitas Udayana [Email: nwidana@yahoo.com] \\ ${ }^{3}$ Program Studi Matematika, Fakultas MIPA-Universitas Udayana [Email: ktjayanegara@unud.ac.id] \\ ${ }^{\S}$ Corresponding Author
}

\begin{abstract}
Ordinary differential equation is one form of differential equations that are often found in everyday life. One form of ordinary differential equations which has non-constant coefficients is the CauchyEuler differential equation. In the nonhomogeneous Cauchy-Euler differential equations, the undetermined coefficient and the parameter variation were the most method that often used to find the particular solution. This paper aimed to show a new solution that was shorter than the previous methods for nonhomogeneous Cauchy-Euler differential equations with the right side was a logarithmic form. The new solution had been proven to produce the same solution as the ordinary solution sought using the undetermined coefficient method.
\end{abstract}

Keywords: Cauchy-Euler differential equation, nonhomogenous differential equations, logarithmic form, particular solution

\section{PENDAHULUAN}

Persamaan diferensial merupakan salah satu konsep matematika yang banyak digunakan dalam ilmu pengetahuan seperti fisika, kimia, industri dan teknik. Persamaan diferensial adalah persamaan yang melibatkan variabel-variabel tidak bebas dan derivatifderivatifnya terhadap variabel bebas. Persamaan diferensial dibagi menjadi dua jenis, yaitu biasa dan parsial (Edwards \& Penney, 2008).

Persamaan diferensial biasa (PDB) adalah suatu persamaan diferensial yang melibatkan hanya satu variabel bebas (Chapra \& Canale, 2015). Penerapan persamaan diferensial dapat ditemukan pada pemodelan perhitungan populasi maupun peluruhan. Salah satu bagian dari PDB adalah persamaan diferensial CauchyEuler.

Persamaan diferensial Cauchy-Euler adalah persamaan diferensial biasa (PDB) berorde$n$ yang menyerupai persamaan polinomial (Batiha \& Batiha, 2011). Penelitian sebelumnya dilakukan oleh Dev dan Gleiser (2002) yang menggunakan persamaan diferensial CauchyEuler tentang efek dari tekanan pada sifat-sifat benda yang diasumsikan simetris berbentuk bola dan terikat oleh gravitasi, seperti bintang. Penelitian tersebut menunjukkan bahwa persamaan diferensial Cauchy-Euler berguna untuk menjelaskan fenomena mengenai gravitasi pada bintang.

Penelitian lainnya yang dilakukan oleh Sabuwala dan Leon (2011) mengenai solusi khusus persamaan Cauchy-Euler polinomial nonhomogen. Penelitian tersebut menghasilkan suatu rumus solusi khusus yang baru untuk menyelesaikan persamaan diferensial CauchyEuler polinomial nonhomogen.

Berdasarkan uraian tersebut penulis melakukan modifikasi kasus pada persamaan diferensial Cauchy-Euler,yang ruas kanannya berbentuk logaritma natural terhadap suatu variabel pada persamaan tersebut. Persamaan yang berisi logaritma natural ini merupakan kasus khusus dari persamaan diferensial Cauchy-Euler.

\section{METODE PENELITIAN}

\section{A. Jenis dan Sumber Data}

Penelitian ini dilakukan dengan mengkaji beberapa literatur berupa buku, jurnal maupun laporan penelitian yang relevan dengan topik 
yang akan dibahas. Langkah awal dalam penelitian ini adalah mempelajari konsep dasar dari persamaan diferensial yang akan digunakan dalam penelitian, meliputi persamaan diferensial biasa dan persamaan diferensial Cauchy-Euler beserta beberapa teori terkait, yaitu fungsi logaritma, turunan fungsi logaritma beserta contohnya.

Setelah mempelajar konsep yang berkaitan, langkah selanjutnya adalah mencari solusi khusus persamaan diferensial Cauchy-Euler dengan ruas kanan persamaannya adalah bentuk logaritma.

\section{B. Teknik Analisis}

Langkah-langkah yang dilakukan adalah sebagai berikut:

1. Menyajikan dua kasus persamaan diferensial Cauchy-Euler yang akan dibahas

2. Mencari solusi untuk masalah dengan bentuk yang sederhana.

3. Menjabarkan beberapa bentuk teorema pendukung sesuai dengan permasalahan.

4. Membentuk solusi untuk kasus umum dari permasalahan.

5. Membuktikan solusi yang diperoleh.

\section{HASIL DAN PEMBAHASAN}

a. Bentuk Permasalahan

Masalah yang dibahas pada penelitian ini adalah persamaan diferensial Cauchy-Euler dengan bentuk sebagai berikut:

$$
\sum_{i=0}^{n} a_{i} t^{i} y^{(i)}=\sum_{j=0}^{m} b_{j} \ln \left(c_{j} t\right)
$$

Proses pencarian solusi dari persamaan tersebut dimulai dengan memberikan beberapa contoh kasus yang menggunakan persamaan tersebut.

\section{b. Contoh Kasus yang Digunakan}

Dalam membentuk solusi persamaan diferensial Cauchy-Euler, ditampilkan terlebih dahulu kasus-kasus yang menggunakan persamaan diferensial Cauchy-Euler sebagai berikut.

Contoh kasus:

1. Tentukan solusi khusus dari $2 t^{2} y^{\prime \prime}+7 t y^{\prime}+$

$$
10 y=3 \ln 2 t \text {. }
$$

2. Tentukan solusi khusus dari $3 t^{3} y^{\prime \prime \prime}+$ $6 t^{2} y^{\prime \prime}+5 t y^{\prime}+9 y=2 \ln 5 t+$

$7 \ln 3 t-11 \ln 7 t$.

Penyelesaian dari kasus di atas dijabarkan sebagai berikut.

1. Tentukan solusi khusus dari $2 t^{2} y^{\prime \prime}+7 t y^{\prime}+$ $10 y=3 \ln 2 t$.

Penyelesaian:

Misalkan: $x=\ln 2 t$ diperoleh:

$$
\frac{d x}{d t}=\frac{1}{t} \operatorname{dan} \frac{d^{2} x}{d t^{2}}=-\frac{1}{t^{2}},
$$

Diperoleh pula

$$
\begin{aligned}
y^{\prime} & =\frac{d y}{d t}=\frac{d y}{d x} \frac{d x}{d t}=\frac{d y}{d x} \frac{1}{t}=\frac{1}{t} \frac{d y}{d x}, \\
y^{\prime \prime} & =\frac{d^{2} y}{d t^{2}}=\frac{d\left(\frac{d y}{d t}\right)}{d t}=\frac{1}{t^{2}}\left(\frac{d^{2} y}{d x^{2}} \frac{d y}{d x}\right),
\end{aligned}
$$

Dengan mensubstitusikan $x, y^{\prime}, y^{\prime \prime}$ ke dalam persamaan yang diberikan maka diperoleh:

$$
\begin{array}{lrl}
2 t^{2}\left(\frac{1}{t^{2}}\left(\frac{d^{2} y}{d x^{2}}-\frac{d y}{d x}\right)\right)+7 t\left(\frac{1}{t} \frac{d y}{d x}\right)+10 y & =3 x \\
\Leftrightarrow & 2 \frac{d^{2} y}{d x^{2}}-2 \frac{d y}{d x}+7 \frac{d y}{d x}+10 y & =3 x \\
\Leftrightarrow & 2 \frac{d^{2} y}{d x^{2}}+5 \frac{d y}{d x}+10 y & =3 x
\end{array}
$$

Selanjutnya misalkan $y=a x^{2}+b x+c$ diperoleh

$$
\frac{d y}{d x}=2 a x+b \text { dan } \frac{d^{2} y}{d x^{2}}=2 a
$$

Dengan mensubstitusikan bentuk $y, \frac{d y}{d x}$ dan $\frac{d^{2} y}{d x^{2}}$ ke dalam persamaan sebelumnya diperoleh

$$
2 \frac{d^{2} y}{d x^{2}}+5 \frac{d y}{d x}+10 y=3 x
$$

$\Leftrightarrow \quad 2(2 a)+5(2 a x+b)+10\left(a x^{2}+b x+c\right)=3 x$

$\Leftrightarrow \quad 4 a+10 a x+5 b+10 a x^{2}+10 b x+10 c=3 x$

$\Leftrightarrow \quad 10 a x^{2}+(10 a+10 b) x+(4 a+5 b+10 c)=3 x$

dengan mencocokkan masing masing suku yang bersesuaian diperoleh:

$$
\begin{aligned}
& \text { I. } \quad 10 a=0 \\
& \Leftrightarrow \quad a=0 \\
& \text { II. } \quad 10 a+10 b=3 \\
& \Leftrightarrow \quad 0+10 b=3 \\
& \Leftrightarrow \quad b=\frac{3}{10}
\end{aligned}
$$


III.

$$
\begin{aligned}
& 4 a+5 b+10 c=0 \\
& \Leftrightarrow \quad 0+5\left(\frac{3}{10}\right)+10 c=0 \\
& \Leftrightarrow \quad \frac{15}{10}+10 c=0 \\
& \Leftrightarrow \quad 10 c=-\frac{15}{10} \\
& \Leftrightarrow \quad c=-\frac{15}{100}
\end{aligned}
$$

Selanjutnya substitusikan nilai $a, b, c$ ke dalam bentuk $y$ yaitu:

$$
\begin{aligned}
y & =a x^{2}+b x+c \\
& =0+\frac{3}{10} x+\left(-\frac{15}{100}\right) \\
& =\frac{3}{10} x-\frac{15}{100} \\
& =\frac{3}{10} \ln 2 t-\frac{15}{100}
\end{aligned}
$$

2. Tentukan solusi khusus dari $3 t^{3} y^{\prime \prime \prime}+$

$$
6 t^{2} y^{\prime \prime}+5 t y^{\prime}+9 y=2 \ln 5 t+
$$

$7 \ln 3 t-11 \ln 7 t$

Penyelesaian:

Persamaan diferensial Cauchy-Euler dipecah menjadi tiga bagian, yaitu

$$
\begin{aligned}
& \text { A. } 3 t^{3} y^{\prime \prime \prime}+6 t^{2} y^{\prime \prime}+5 t y^{\prime}+9 t= \\
& \quad 2 \ln 5 t \\
& \text { B. } 3 t^{3} y^{\prime \prime \prime}+6 t^{2} y^{\prime \prime}+5 t y^{\prime}+9 y= \\
& \quad 7 \ln 3 t \\
& \text { C. } 3 t^{3} y^{\prime \prime \prime}+6 t^{2} y^{\prime \prime}+5 t y^{\prime}+9 y= \\
& \quad-11 \ln 7 t
\end{aligned}
$$

Misalkan $x=\ln k t$ diperoleh

$$
\frac{d x}{d t}=\frac{1}{t}, \frac{d^{2} x}{d t^{2}}=-\frac{1}{t^{2}} \text { dan } \frac{d^{3} x}{d t^{3}}=\frac{2}{t^{3}}
$$

diperoleh pula

$$
\begin{aligned}
y^{\prime} & =\frac{d y}{d t}=\frac{d y}{d x} \cdot \frac{d x}{d t}=\frac{d y}{d x} \cdot \frac{1}{t}=\frac{1}{t} \frac{d y}{d x} \\
y^{\prime \prime} & =\frac{d^{2} y}{d t^{2}}=\frac{d\left(\frac{d y}{d t}\right)}{d t} \\
& =\frac{d\left(\frac{1}{t} \frac{d y}{d x}\right)}{d t} \\
& =\frac{1}{t^{2}}\left(\frac{d^{2} y}{d x^{2}}-\frac{d y}{d x}\right) \\
y^{\prime \prime \prime} & =\frac{d^{3} y}{d t^{3}}=\frac{d\left(\frac{d^{2} y}{d t^{2}}\right)}{d t} \\
& =\frac{d\left(\frac{1}{t^{2}}\left(\frac{d^{2} y}{d x^{2}}-\frac{d y}{d x}\right)\right)}{d t}
\end{aligned}
$$

$$
=\frac{1}{t^{3}}\left(\frac{d^{3} y}{d x^{3}}-3 \frac{d^{2} y}{d x^{2}}+2 \frac{d y}{d x}\right)
$$

dengan mensubstitusikan bentuk $y, y^{\prime}, y^{\prime \prime}$, dan $y^{\prime \prime \prime}$ ke dalam ruas kiri persamaan (4.1), (4.2), dan (4.3) diperoleh

$$
\begin{aligned}
& 3 t^{3} y^{\prime \prime \prime}+6 t^{2} y^{\prime \prime}+5 t y^{\prime}+9 y \\
&= 3 t^{3} \cdot \frac{1}{t^{3}}\left(\frac{d^{3} y}{d x^{3}}-\frac{3 d^{2} y}{d x^{2}}+2 \frac{d y}{d x}\right) \\
&+6 t^{2} \frac{1}{t^{2}}\left(\frac{d^{2} y}{d x^{2}}-\frac{d y}{d x}\right)+5 t \cdot \frac{1}{t}\left(\frac{d y}{d x}\right)+9 y \\
&= 3 \frac{d^{3} y}{d x^{3}}-3 \frac{d^{2} y}{d x^{2}}+5 \frac{d y}{d x}+9 y
\end{aligned}
$$

Sehingga diperoleh

A. Misalkan $x=\ln 5 t$ maka persamaan (4.2) dapat ditulis sebagai

$$
3 \frac{d^{3} y}{d x^{3}}-3 \frac{d^{2} y}{d x^{2}}+5 \frac{d y}{d x}+39 y=2 x
$$

B. Misalkan $x=\ln 3 t$ maka persamaan (4.3) dapat ditulis sebagai

$$
3 \frac{d^{3} y}{d x^{3}}-3 \frac{d^{2} y}{d x^{2}}+5 \frac{d y}{d x}+9 y=7 x
$$

C. Misalkan $x=\ln 7 x$ maka persamaan (4.4) dapat ditulis sebagai

$$
3 \frac{d^{3} y}{d x^{3}}-3 \frac{d^{2} y}{d x^{2}}+5 \frac{d y}{d x}+9 y=-11 x
$$

Selanjutnya misalkan $y=a x^{3}+b x^{2}+c x+d$ diperoleh

$$
\begin{aligned}
& \frac{d y}{d x}=3 a x^{2}+2 b x+c, \\
& \frac{d^{2} y}{d x^{2}}=6 a x+2 b, \\
& \frac{d^{3} y}{d x^{3}}=6 a,
\end{aligned}
$$

Dengan mensubstitusikan bentuk, $\frac{d y}{d x}, \frac{d^{2} y}{d x^{2}}, \frac{d^{3} y}{d x^{3}}$ ke dalam ruas kiri dari persamaan (4.5), (4.6), (4.7) diperoleh

$$
\begin{aligned}
& 3 \frac{d^{3} y}{d x^{3}}-3 \frac{d^{2} y}{d x^{2}}+5 \frac{d y}{d x}+9 y \\
= & 3 \cdot 6 a-3(6 a x+2 b) \\
& +5\left(3 a x^{2}+2 b x+c\right) \\
& +9\left(a x^{3}+b x^{2}+c x+d\right) \\
= & 9 a x^{3}+(15 a+9 b) x^{2} \\
& +(-18 a+10 b+9 c) x \\
& +(18 a-6 b+5 c+9 d)
\end{aligned}
$$


Berdasarkan penjabaran di atas, persamaan (4.5), (4.6), dan (4.7) dapat ditulis menjadi bentuk persamaan umum, yaitu:

$9 a x^{3}+(15 a+9 b) x^{2}$

$+(-18 a+10 b+9 c) x$

$+(18 a-6 b+5 c+9 d)=p x$

dengan mencocokkan masing-masing suku yang bersesuaian diperoleh

I. $\quad 9 a=0$

$$
\Leftrightarrow \quad a=0
$$

II.

$$
\begin{array}{rlrl} 
& & 15 a+9 b & =0 \\
\Leftrightarrow & 0+9 b & =0 \\
\Leftrightarrow & b & =0
\end{array}
$$

III. $-18 a+10 b+9 c=p$

$$
\begin{aligned}
\Leftrightarrow & & 0+0+9 c & =p \\
\Leftrightarrow & & c & =\frac{p}{9}
\end{aligned}
$$

IV.

$$
\begin{aligned}
& & 18 a-6+5 c+9 d & =0 \\
\Leftrightarrow & & 0-0+5\left(\frac{p}{9}\right)+9 d & =0 \\
\Leftrightarrow & & \frac{5}{9} p+9 d & =0 \\
\Leftrightarrow & & 9 d & =-\frac{5}{9} p \\
\Leftrightarrow & & d & =-\frac{5}{81} p
\end{aligned}
$$

Ini berarti,

A. Untuk persamaan (4.5) dapat dicari solusi khusus sebagai berikut

$$
\begin{aligned}
& 3 \frac{d^{3} y}{d x^{3}}-3 \frac{d^{2} y}{d x^{2}}+5 \frac{d y}{d x}+9 y=2 x \\
& p=2 \\
& a=0 \\
& b=0 \\
& c=\frac{p}{9}=\frac{2}{9} \\
& d=-\frac{5}{81} p=-\frac{10}{81} \\
& y_{A}=a x^{3}+b x^{2}+c x+d \\
& =0+0+\frac{2}{9} x+\left(-\frac{10}{81}\right) \\
& =\frac{2}{9} \ln 5 t-\frac{10}{81}
\end{aligned}
$$

B. Untuk persamaan (4.6) dapat dicari solusi khusus sebagai berikut

$$
3 \frac{d^{3} y}{d x^{3}}-3 \frac{d^{2} y}{d x^{2}}+5 \frac{d y}{d x}+9 y=7 x
$$

$$
\begin{aligned}
& p=7 \\
& a=0 \\
& b=0 \\
& \text { c }=\frac{p}{9}=\frac{7}{9} \\
& d=-\frac{5}{81} p=-\frac{35}{81} \\
& y_{B}=a x^{3}+b x^{2}+c x+d \\
& =0+0+\frac{7}{9} x+\left(-\frac{35}{81}\right) \\
& =\frac{7}{9} \ln 3 t-\frac{35}{81} \\
& 3 \frac{d^{3} y}{d x^{3}}-3 \frac{d^{2} y}{d x^{2}}+5 \frac{d y}{d x}+9 y=-11 x \\
& p=-11 \\
& a=0 \\
& b=0 \\
& \text { c }=\frac{p}{9}=-\frac{11}{9} \\
& d=-\frac{5}{81} p=\frac{55}{81} \\
& y_{c}=a x^{3}+b x^{2}+c x+d \\
& =0+0+\left(-\frac{11}{9}\right) x+\frac{55}{81} \\
& =-\frac{11}{9} \ln 7 t+\frac{55}{81}
\end{aligned}
$$

C. Untuk persamaan (4.7) dapat dicari solusi

Diperoleh

$$
\begin{aligned}
y_{p}= & y_{A}+y_{B}+y_{C} \\
= & \frac{2}{9} \ln 5 t-1081+79 \ln 3 t-3581 \\
& +\left(-\frac{11}{9} \ln 7 t\right)+\frac{55}{81} \\
= & \frac{2}{9} \ln 5 t+\frac{7}{9} \ln 3 t-\frac{11}{9} \ln 7 t+\frac{10}{81}
\end{aligned}
$$

Dalam pembahasan akan memakai teoremateorema berikut:

\section{Teorema Turunan Logaritma Orde ke - i}

Diberikan $y=A \ln (k t)+B$

maka $y^{(i)}=\frac{(-1)^{i-1}(i-1) !}{t^{i}} \mathrm{~A}$

Bukti:

Teorema ini akan dibuktikan menggunakan induksi matematika

Untuk $i=1$ maka

$y^{\prime}=A \frac{1}{t}=\frac{A}{t}$ 
Di lain pihak

$$
\begin{aligned}
y^{\prime} & =\frac{(-1)^{1-1}(1-1) !}{t} A \\
& =\frac{(-1)^{0} 0 !}{t} A \\
& =\frac{1 \times 1}{t} A \\
& =\frac{A}{t}
\end{aligned}
$$

Terbukti benar untuk $i=1$

Selanjutkan diasumsikan benar untuk $i=k$ sehingga

$$
y^{(k)}=\frac{(-1)^{k-1}(k-1) !}{t^{k}} A
$$

Akan dibuktikan untuk $i=k+1$.

$$
\begin{aligned}
y^{(k+1)} & =\left(\frac{(-1)^{k-1}(k-1) !}{t^{k}} A\right)^{\prime} \\
& =\left((-1)^{k-1}(k-1) ! A t^{-k}\right)^{\prime} \\
& =(-1)^{k-1}(k-1) ! A(-k) t^{-k-1} \\
& =\frac{(-1)^{k-1}(-1)(k-1) ! k A}{t^{k+1}} \\
& =\frac{(-1)^{k} k ! A}{t^{k+1}}
\end{aligned}
$$

Di lain pihak

\section{Teorema Turunan Orde ke-k}

Jika $x=\ln b t, y=f(t)$ dan $k=1,2, \cdots$ maka

$$
\frac{d^{k} y}{d t^{k}}=\frac{1}{t^{k}} \sum_{j=1}^{k} \frac{P^{j-1}(k-1, k-1)}{(j-1) !}(-1)^{k-j} \frac{d^{j} y}{d x^{j}}
$$

Bukti:

Akan dibuktikan menggunakan induksi matematika.

Untuk $k=1$

Akan dibuktikan $\frac{d y}{d t}=\frac{1}{t} \frac{P(0,0)(-1)^{0}}{0 !} \frac{d y}{d x}$

$$
\begin{aligned}
& =\frac{1}{t} \frac{1(-1)^{0}}{0 !} \frac{d y}{d x} \\
& =\frac{1}{t} \frac{d y}{d x}
\end{aligned}
$$

$$
\begin{aligned}
x & =\ln b t \\
\frac{d x}{d t} & =\frac{1}{t} \\
\frac{d y}{d t} & =\frac{d y}{d x} \frac{d x}{d t}=\frac{1}{t} \frac{d y}{d x}
\end{aligned}
$$

Terbukti untuk $k=1$

Asumsikan benar untuk $k=n-1$ yaitu

$$
\begin{aligned}
& \frac{d^{n-1} y}{d t^{n-1}} \\
& =\frac{1}{t^{n-1}} \sum_{j=1}^{n-1} \frac{P^{j-1}(n-2, n-2)}{(j-1) !}(-1)^{n-j-1} \frac{d^{j} y}{d x^{j}}
\end{aligned}
$$

Akan dibuktikan untuk $k=n$ berlaku

$$
\frac{d^{n} y}{d t^{n}}=\frac{1}{t^{n}} \sum_{j=1}^{n} \frac{P^{j-1}(n-1, n-1)(-1)^{n-j}}{(j-1) !} \frac{d^{j} y}{d x^{j}}
$$

$\frac{d^{n} y}{d t^{n}}=\frac{d\left(\frac{d^{n-1} y}{d t^{n-1}}\right)}{d t}$

$$
=\frac{d\left(\frac{1}{t^{n-1}}\right) \sum_{j=1}^{n-1} \frac{P^{(j-1)}(n-2, n-2)}{(j-1) !}}{d t}
$$$$
+\frac{1}{t^{n-1}}
$$$$
\frac{d\left(\sum_{j=1}^{n-1} \frac{P^{(j-1)}(n-2, n-2)}{(j-1) !}(-1)^{n-j-1}\right.}{d t}
$$

$\left.\frac{d^{j} y}{d x^{j}}\right)$

$$
=\frac{1}{t^{n}} \sum_{j=1}^{n-1}(n
$$$$
\text { -1) } \frac{P^{(j-1)}(n-2, n-2)}{(j-1) !}(-1)^{n-j} \frac{d^{j} y}{d x^{j}}
$$$$
+\frac{1}{t^{n-1}} \sum_{j=1}^{n-1} \frac{P^{(j-1)}(n-2, n-2)}{(j-1) !} \frac{d^{j+1} y}{d x^{j+1}}
$$$$
(-1)^{n-j-1} \cdot \frac{1}{t}
$$$$
=\frac{1}{t^{n}} \sum_{j=1}^{n-1}(n-1) \frac{P^{(j-1)}(n-2, n-2)}{(j-1) !}
$$$$
(-1)^{n-j} \frac{d^{j} y}{d x^{j}}
$$$$
+\frac{1}{t^{n}} \sum_{j=1}^{n-1} \frac{P^{(j-1)}(n-2, n-2)}{(j-1) !}
$$$$
(-1)^{n-j-1} \frac{d^{j+1} y}{d x^{j+1}}
$$

dengan menguraikan diperoleh

$\sum_{j=1}^{n-1}(n-1) \frac{P^{(j-1)}(n-2, n-2)}{(j-1) !}(-1)^{n-j} \frac{d^{j} y}{d x^{j}}$ 


$$
\begin{aligned}
= & \frac{(n-1) P(n-2, n-2)}{0 !}(-1)^{n-1} \frac{d y}{d x} \\
+ & \sum_{j=2}^{n-1}(n-1) \frac{P^{(j-1)}(n-2, n-2)}{(j-1) !} \\
= & \frac{(-1)^{n-j} \frac{d^{j} y}{d x^{j}}}{n(n-1, n-1)}(-1)^{n-1} \frac{d y}{d x} \\
& +\sum_{j=2}^{n-1}(n-1) \frac{P^{(j-1)}(n-2, n-2)}{(j-1) !} \\
& (-1)^{n-j} \frac{d^{j} y}{d x^{j}}
\end{aligned}
$$

sehingga

$\sum_{j=1}^{n-1} \frac{P^{(j-1)}(n-2, n-2)}{(j-1) !}(-1)^{n-j-1} \frac{d^{j+1} y}{d x^{j+1}}$

$=\sum_{j=2}^{n} \frac{P^{(j-2)}(n-2, n-2)}{(j-2) !}(-1)^{n-j-2} \frac{d^{j} y}{d x^{j}}$

$=\sum_{j=2}^{n} \frac{(j-1) P^{(j-2)}(n-2, n-2)}{(j-1)(j-2) !} \frac{(-1)^{n-j}}{(-1)^{2}} \frac{d^{j} y}{d x^{j}}$

$=\sum_{j=2}^{n} \frac{(j-1) P^{(j-2)}(n-2, n-2)}{(j-1) !}(-1)^{n-j} \frac{d^{j} y}{d x^{j}}$

$=\sum_{j=2}^{n-1} \frac{(j-1) P^{(j-2)}(n-2, n-2)}{(j-1) !}(-1)^{n-j} \frac{d^{j} y}{d x^{j}}$

$+\frac{(n-1) P^{(n-2)}(n-2, n-2)}{(n-1) !}(-1)^{n-n} \frac{d^{j} y}{d x^{j}}$

$=\sum_{j=2}^{n-1} \frac{(j-1) P^{(j-2)}(n-2, n-2)}{(j-1) !}(-1)^{n-j} \frac{d^{j} y}{d x^{j}}$

$+\frac{P^{(n-1)}(n-1, n-1)}{(n-1) !} \frac{d^{n} y}{d x^{n}}$

Kembali ke (4.9)

$$
\begin{aligned}
\frac{1}{t^{n}} \sum_{j=1}^{n-1} \frac{(n-1) P^{(j-1)}(n-2, n-2)}{(j-1) !}(-1)^{n-j} \frac{d^{j} y}{d x^{j}} \\
+\frac{1}{t^{n}} \sum_{j=1}^{n-1} \frac{P^{(j-1)}(n-2, n-2)}{(j-1) !}(-1)^{n-j-1} \frac{d^{j+1} y}{d x^{j+1}} \\
=\frac{1}{t^{n}}\left(\sum_{j=1}^{n-1} \frac{(n-1) P^{(j-1)}(n-2, n-2)}{(j-1) !}(-1)^{n-j}\right. \\
\quad \frac{d^{j} y}{d x^{j}}+\sum_{j=1}^{n-1} \frac{P^{(j-1)}(n-2, n-2)}{(j-1) !}(-1)^{n-j-1} \\
\left.\quad \frac{d^{j+1} y}{d x^{j+1}}\right)
\end{aligned}
$$

$=\frac{1}{t^{n}}\left(\sum_{j=1}^{n} \frac{P^{(j-1)}(n-1, n-1)}{(j-1) !}(-1)^{n-j} \frac{d^{j} y}{d x^{j}}\right)$

Terbukti.

\section{Teorema Penjumlahan Turunan Orde ke-k}

Jika $x=\ln b t$ maka

$$
\begin{aligned}
& \sum_{k=1}^{n} a_{k} t^{k} \frac{d^{k} y}{d t^{k}} \\
& =\sum_{k=1}^{n} \sum_{j=1}^{k} a_{k} \frac{P^{(j-1)}(k-1, k-1)}{(j-1) !}(-1)^{k-j} \frac{d^{j} y}{d x^{j}}
\end{aligned}
$$

Bukti:

$$
\begin{aligned}
\sum_{k=1}^{n} a_{k} t^{k} \frac{d^{k} y}{d t^{k}} & =\sum_{k=1}^{n} a_{k} t^{k} \frac{1}{t^{k}} \sum_{j=1}^{k} \frac{P^{(j-1)}(k-1,}{(j-1) !} \\
& \frac{k-1)}{(-1)^{k-j} \frac{d^{j} y}{d x^{j}}} \\
= & \sum_{k=1}^{n} a_{k} \sum_{j=1}^{k} \frac{P^{(j-1)}(k-1, k-1)}{(j-1) !} \\
& (-1)^{k-j} \frac{d^{j} y}{d x^{j}} \\
= & \sum_{k=1}^{n} \sum_{j=1}^{k} a_{k} \frac{P^{(j-1)}(k-1, k-1)}{(j-1) !} \\
& (-1)^{k-j} \frac{d^{j} y}{d x^{j}}
\end{aligned}
$$

Terbukti benar.

\section{Teorema Superposisi}

Jika $f=f_{1}$ adalah solusi dari

$$
\sum_{i=0}^{n} g_{i} f^{(i)}=h_{1}
$$

dan $f=f_{2}$ adalah solusi dari

$\sum_{i=0}^{n} g_{i} f^{(i)}=h_{2}$

maka $f=f_{1}+f_{2}$ adalah solusi dari

$\sum_{i=0}^{n} g_{i} f^{(i)}=h_{1}+h_{2}$

Bukti:

$$
\begin{aligned}
& f^{(i)}=f_{1}^{(i)}+f_{2}^{(i)} \\
& \Leftrightarrow \sum_{i=0}^{n} g_{i} f_{1}^{(i)}+\sum_{i=0}^{n} g_{i} f_{2}^{(i)}=h_{1}+h_{2}
\end{aligned}
$$




$$
\begin{aligned}
& \Leftrightarrow \sum_{i=0}^{n} g_{i}\left(f_{1}^{(i)}+f_{2}^{(i)}\right)=h_{1}+h_{2} \\
& \Leftrightarrow \sum_{i=0}^{n} g_{i} f^{(i)}=h_{1}+h_{2}
\end{aligned}
$$

Terbukti.

\section{Teorema 1}

Diberikan persamaan diferensial Cauchy-Euler nonhomogen dengan ruas kanan adalah suatu logaritma, yaitu

$$
\sum_{i=0}^{n} a_{i} t^{i} y^{(i)}=b \ln (c t)
$$

Maka solusi khususnya adalah

$$
y_{p}=\frac{b}{a_{0}} \ln (c t)-\frac{b}{a_{0}^{2}} \sum_{i=1}^{n} a_{i}(-1)^{i-1}(i-1) !
$$

Bukti:

Pertama persamaan 4.10 dipecah menjadi:

$$
\left(\sum_{i=1}^{n} a_{i} t^{i} y^{(i)}\right)+a_{0} y=b \ln (c t)
$$

Misalkan $x=\ln c t$ dan berdasarkan teorema penjumlahan turunan orde $\mathrm{ke}-\mathrm{k}$, persamaan (4.11) dapat ditransformasi menjadi

$\sum_{i=1}^{n} \sum_{j=1}^{i} a_{i} \frac{P^{(j-1)}(i-1, i-1)}{(j-1) !}(-1)^{i-j} \frac{d^{j} y}{d x^{j}}$ $+a_{0} y=b x$

Bentuk di atas adalah bentuk persamaan diferensial nonhomogen dengan ruas kanan berbentuk polynomial sehingga solusinya dapat dibentuk menjadi bentuk polynomial, yaitu:

$y=r x+s$

$\frac{d y}{d x}=r$

$\frac{d^{j} y}{d x^{j}}=0, j=2,3, \cdots, n$

Dengan mensubstitusikan solusi bentuk polinomial dan turunannya ke dalam persamaan (4.12) maka diperoleh:

$$
\begin{aligned}
& \sum_{i=1}^{n}\left(\frac{a_{i} P(i-1, i-1)}{0 !}(-1)^{i-1} r+0\right) \\
& +a_{0}(r x+s)=b x \\
& \Leftrightarrow \sum_{i=1}^{n} a_{i}(i-1) !(-1)^{i-1} r+a_{0} r x+s=b x
\end{aligned}
$$

$\Leftrightarrow a_{0} r x+\left(\sum_{i=1}^{n} a_{i}(i-1) !(-1)^{i-1} r+s\right)=b x$

Diperoleh:

$a_{0} r x=b x$

$\Leftrightarrow r=\frac{b}{a_{0}}$

Akibatnya

$$
\begin{aligned}
& \sum_{i=1}^{n} a_{i}(i-1) !(-1)^{i-1} r+s=0 \\
& s=-\sum_{i=1}^{n} a_{i}(i-1) !(-1)^{i-1} r \\
& =-r \sum_{i=1}^{n} a_{i}(-1)^{i-1}(i-1) ! \\
& =-\frac{b}{a_{0}} \sum_{i=1}^{n} a_{i}(-1)^{i-1}(i-1) !
\end{aligned}
$$

Solusinya berupa

$$
\begin{aligned}
y & =r x+s \\
& =\frac{b}{a_{0}} \ln c t-\frac{b}{a_{0}} \sum_{i=1}^{n} a_{i}(-1)^{i-1}(i-1) !
\end{aligned}
$$

Terbukti.

\section{Teorema 2}

Berikut akan diuraikan persamaan diferensial Cauchy-Euler yang berisi logaritma natural dan merupakan masalah inti yang ingin dijawab. Diberikan persamaan diferensial Cauchy-Euler berbentuk

$\sum_{i=0}^{n} a_{i} t^{i} y^{(i)}=\sum_{j=0}^{m} b_{j} \ln \left(c_{j} t\right)$

Dengan solusi khusus

$$
\begin{aligned}
y_{p}= & \sum_{j=0}^{m} \frac{b_{j}}{a_{o}} \ln c_{j} t \\
& -\frac{1}{a_{0}^{2}}\left(\sum_{j=0}^{m} b_{j}\right)\left(\sum_{i=1}^{n} a_{i}(-1)^{i-1}(i-1) !\right)
\end{aligned}
$$

Akan dibuktian rumus di atas

Bukti:

$$
\sum_{i=0}^{n} a_{i} t^{i} y^{(i)}=\sum_{j=0}^{m} b_{j} \ln \left(c_{j} t\right)
$$

Dipecah menjadi

$$
\sum_{i=0}^{n} a_{i} t^{i} y^{(i)}=b_{0} \ln \left(c_{0} t\right) \text { memiliki solusi }
$$




$$
\begin{aligned}
& y_{0}=\frac{b_{0}}{a_{0}} \ln \left(c_{0} t\right)-\frac{b_{0}}{a_{0}^{2}} \sum_{i=1}^{n} a_{i}(-1)^{i-1}(i-1) ! \\
& \sum_{i=0}^{n} a_{i} t^{i} y^{(i)}=b_{1} \ln \left(c_{1} t\right) \text { memiliki solusi } \\
& y_{1}=\frac{b_{1}}{a_{0}} \ln \left(c_{1} t\right)-\frac{b_{1}}{a_{0}^{2}} \sum_{i=1}^{n} a_{i}(-1)^{i-1}(i-1) ! \\
& \quad \vdots \\
& \sum_{i=0}^{n} a_{i} t^{i} y^{(i)}=b_{m} \ln \left(c_{m} t\right) \text { memiliki solusi } \\
& y_{m}=\frac{b_{m}}{a_{0}} \ln \left(c_{m} t\right)-\frac{b_{m}}{a_{0}^{2}} \sum_{i=1}^{n} a_{i}(-1)^{i-1}(i-1) !
\end{aligned}
$$

Menurut prinsip superposisi akan membentuk

$$
\begin{aligned}
y_{p}= & y_{0}+y_{1}+\cdots y_{m} \\
= & \left(\frac{b_{0}}{a_{0}} \ln \left(c_{0} t\right)-\frac{b_{0}}{a_{0}^{2}} \sum_{i=1}^{n} a_{i}(-1)^{i-1}(i-1) !\right) \\
& +\left(\frac{b_{1}}{a_{0}} \ln \left(c_{1} t\right)-\frac{b_{1}}{a_{0}^{2}} \sum_{i=1}^{n} a_{i}(-1)^{i-1}(i-1) !\right) \\
& +\cdots \\
& +\left(\frac{b_{m}}{a_{0}} \ln \left(c_{m} t\right)-\frac{b_{m}}{a_{0}^{2}} \sum_{i=1}^{n} a_{i}(-1)^{i-1}(i\right. \\
= & \sum_{j=0}^{m} \frac{b_{j}}{a_{0}} \ln \left(c_{j} t\right) \\
& -\frac{1}{a_{0}^{2}}\left(\sum_{j=0}^{m} b_{j}\right)\left(\sum_{i=1}^{n} a_{i}(-1)^{i-1}(i\right. \\
- & 1) !)
\end{aligned}
$$

Jadi solusi khusus yang diberikan terbukti benar.

Berikut ini teorema 1 dan teorema 2 digunakan untuk menyelesaikan persamaan diferensial Cauchy-Euler pada dua kasus yang sebelumnya telah diselesaikan dengan metode biasa.

Untuk pembuktian solusi khusus baru yang telah dibentuk maka solusi khusus tersebut diterapkan pada contoh kasus yang telah diberikan sebelumnya.
Contoh kasus:

1. Tentukan solusi khusus dari $2 t^{2} y^{\prime \prime}+7 t y^{\prime}+$ $10 y=3 \ln 2 t$.

2. Tentukan solusi khusus dari $3 t^{3} y^{\prime \prime \prime}+$ $6 t^{2} y^{\prime \prime}+5 t y^{\prime}+9 y=2 \ln 5 t+$ $7 \ln 3 t-11 \ln 7 t$.

Solusi dari kasus yang diberikan adalah sebagai berikut :

1. Diketahui $2 t^{2} y^{\prime \prime}+7 t y^{\prime}+10 y=3 \ln 2 t$

$a_{0}=10 \quad a_{1}=7 \quad a_{2}=2 \quad b=3 \quad c=2$ Sehingga solusi khususnya berupa

$$
\begin{aligned}
y_{p}= & \sum_{j=0}^{m} \frac{b_{j}}{a_{o}} \ln \left(c_{j} t\right) \\
& -\frac{1}{a_{0}^{2}}\left(\sum_{j=0}^{m} b_{j}\right)\left(\sum_{i=1}^{n} a_{i}(-1)^{i-1}(i-1) !\right) \\
= & \frac{b}{a_{0}} \ln (c t)-\frac{1}{a_{0}^{2}}(b)\left(a_{1}(-1)^{1-1}(1-1) !\right. \\
& \left.+a_{2}(-1)^{2-1}(2-1) !\right) \\
= & \frac{3}{10} \ln (2 t) \\
& -\frac{1}{10^{2}} \cdot 3(7 \cdot 1 \cdot 1+2(-1) \cdot 1) \\
= & \frac{3}{10} \ln 2 t-\frac{1}{100} \cdot 3(7-2) \\
= & \frac{3}{10} \ln 2 t-\frac{15}{100}
\end{aligned}
$$

2. Diketahui $3 t^{3} y^{\prime \prime \prime}+6 t^{2} y^{\prime \prime}+5 t y^{\prime}+9 y=$ $2 \ln 5 t+7 \ln 3 t-11 \ln 7 t$

$$
\begin{array}{llll}
a_{0}=9 & a_{1}=5 & a_{2}=6 & a_{3}=3 \\
b_{0}=2 & b_{1}=7 & b_{2}=-11 & \\
c_{0}=5 & c_{1}=3 & c_{2}=7 &
\end{array}
$$

Sehingga solusi khususnya berupa

$$
\begin{aligned}
y_{p}= & \left(\frac{b_{0}}{a_{0}} \ln \left(c_{0} t\right)+\frac{b_{1}}{a_{0}} \ln \left(c_{1} t\right)+\frac{b_{2}}{a_{0}} \ln \left(c_{2} t\right)\right. \\
& \left.+\frac{b_{3}}{a_{0}} \ln \left(c_{3} t\right)\right)-\frac{1}{a_{0}^{2}}\left(b_{0}+b_{1}+b_{2}\right) \\
& \cdot\left(a_{1}(-1)^{1-1}(1-1) !\right. \\
& +a_{2}(-1)^{2-1}(2-1) ! \\
& \left.+a_{3}(-1)^{3-1}(3-1) !\right) \\
= & \left(\frac{2}{9} \ln (5 t)+\frac{7}{9} \ln (3 t)-\frac{11}{9} \ln (7 t)\right. \\
& \left.+\frac{0}{9} \ln (0 t)\right)-\frac{1}{81}(2+7-11)
\end{aligned}
$$




$$
\begin{aligned}
& \cdot(5(1) 1+6(-1) \cdot 1+3 \cdot 1 \cdot 2) \\
= & \frac{2}{9} \ln 5 t+\frac{7}{9} \ln 3 t \\
& -\frac{11}{9} \ln 7 t+\frac{10}{81}
\end{aligned}
$$

Diperoleh bahwa solusi khusus yaitu persamaan (4.1) sama dengan (4.14) dan persamaan (4.8) sama dengan (4.15). Jadi terbukti bahwa solusi khusus baru sama dengan solusi khusus yang diperoleh dengan cara biasa.

\section{KESIMPULAN DAN SARAN}

Berdasarkan uraian pada hasil dan pembahasan, berikut diberikan kesimpulan dan saran sehubungan dengan penelitian.

\section{Kesimpulan}

Solusi khusus yang diperoleh pada penelitian ini mampu menyelesaikan persamaan diferensial Cauchy-Euler yang ruas kanannya berbentuk logaritma. Solusi tersebut sudah dibuktikan dan sama dengan solusi yang diperoleh dengan menggunakan langkah biasa. Keunggulan solusi baru ini adalah bentuknya yang lebih sederhana dan lebih cepat daripada solusi khusus dengan langkah biasa.

\section{Saran}

Berdasarkan hasil yang telah diperoleh, penulis sudah melakukan perhitungan abstrak untuk mencari dan membuktikan solusi yang diinginkan serta hasilnya sudah teruji. Disarankan untuk penelitian selanjutnya yaitu dengan mengambangkan bentuk logaritma natural agar lebih kompleks seperti perpangkatan pada logaritma natural.

\section{DAFTAR PUSTAKA}

Batiha, K. \& Batiha, B., 2011. A Reliable Algorithm For Solving Cauchy-Euler Differential Equation. Australian Journal of Basic and Applied Sciences, 5(11), pp. 2161-2169.

Chapra, S. C. \& Canale, R. P., 2015. Numerical Methods for Engineers. 7 ed. New York: McGraw-Hill Education.

Dev, K. \& Gleiser, M., 2002. Anisotropic Stars: Exact Solutions. General Relativity and Gravitation, 34(11), pp. 1793-1818.

Edwards, C. H. \& Penney, D. E., 2008. Elementary Differential Equations. 6 ed. New Jersey: Pearson Education.

KBBI, 2016. Kamus Besar Bahasa Indonesia. [Online]

Available at: https://kbbi.kemdikbud.go.id/ [Accessed 25 April 2019].

Oxford, 2019. Oxford English Dictionary. [Online]

Available at: https://en.oxforddictionaries.com/ [Accessed 27 April 2019].

Sabuwala, A. H. \& Leon, D. D., 2011. Particular Solution To The Euler-Cauchy Equation With Polynomial NonHomogeneities. Discrete And Continuous Dynamical Systems, pp. 1271-1278.

Wright, C., 1990. Wittgenstein on Mathematical Proof. Royal Institute of Philosophy Supplement, Volume 28, pp. 79-99. 